\title{
Coğrafi Bilgi Sistemleri Ağ Analizinde Anlık Dinamik Sorgulama Simülasyonu
}

\author{
Ahmet USLU ${ }^{1 *}$, Hasan Burak ÖZMEN², Hakan UYGUÇGiL ${ }^{3}$ \\ 1,2 Eskişehir Teknik Üniversitesi, Lisansüstü Eğitim Enstitüsü, Uzaktan Algılama ve Coğrafi Bilgi Sistemleri Ana Bilim Dalı, \\ Eskişehir. \\ ${ }^{3}$ Eskişshir Teknik Üniversitesi, Yer ve Uzay Bilimleri Enstitüsü, Eskişsehir.
}

*Sorumlu Yazar e-posta: ${ }^{1}$ ahmet.uslu1@dpu.edu.tr. ORCID ID: https://orcid.org/0000-0001-8745-423X

2hbozmen@eskisehir.edu.tr ORCID ID: https://orcid.org/0000-0002-5740-4618

33ugucgil@eskisehir.edu.tr ORCID ID: https://orcid.org/0000-0003-3100-0129

Geliş Tarihi: 30.07.2019; Kabul Tarihi: 23.10.2019

\begin{tabular}{|c|c|}
\hline & z \\
\hline $\begin{array}{c}\text { Anahtar kelimeler } \\
\text { Coğrafi bilgi sistemleri; } \\
\text { Ağ analizi; } \\
\text { Nesnelerin interneti; } \\
\text { Anlık dinamik arama; } \\
\text { Cadde-üstü otopark; } \\
\text { En uygun güzergâh. }\end{array}$ & $\begin{array}{l}\text { Günümüzde, araç sayısındaki artış, şehir merkezlerinde trafik sıkışıklığına neden olarak hayatı olumsuz } \\
\text { yönde etkilemektedir. Araç sayısındaki artışa bağlı olarak kent merkezinde park yeri bulmak zorlaşırken, } \\
\text { altyapı eksikliği ve otopark yeri seçiminin hatalı olması trafiği daha da yoğunlaştırmaktadır. Yaşanabilir } \\
\text { kent bağlamında yerel yönetimlerin, otopark gereksinimlerini karşılamak ve trafik sıkışıkığını gidermek } \\
\text { adına çözüm üretmeleri gerekmektedir. Çalışmada, coğrafi bilgi teknolojileri ile cadde üstü otopark } \\
\text { noktalarına yönelik uygun güzergâh seçiminin önemi ve yararları incelenmiştir. Çalışma bölgesi olarak } \\
\text { belirlenen Eskişehir İli Tepebaşı İlçesi, Eskibağlar Mahallesi, Fabrikalar Caddesi ve Hoşnudiye Mahallesi, } \\
\text { Kızılcıklı Mahmut Pehlivan Caddesi üzerinde bulunan cadde üstü otopark noktalarına, ağ analizi yöntemi } \\
\text { kullanarak sürücülerin çeşitli senaryolarla otopark noktalarına ulaşmalarına yönelik güzergâh çalışması } \\
\text { yapılmıştır. Çalışma sonucunda Coğrafi Bilgi Sistemleri (CBS) ağ analizinde anlık dinamik arama } \\
\text { simülasyonu uygulanmış, yöntemin park yeri arama zamanını en az indirgediği gözlenmiştir. }\end{array}$ \\
\hline
\end{tabular}

\section{Instant Dynamic Search Simulation in Geographic Information Systems Network Analysis}

\begin{abstract}
Keywords

Geographic information systems; Network analysis; Internet of things; Instant dynamic search; On-street parking; Optimum route.

Today, the rise in the number of vehicles affects life negatively by traffic congestion in city centers. Due to the increase in the number of vehicles, it becomes challenging to find out the parking area in downtown. The lack of infrastructure and awkward parking area locations densify the traffic. In the meaning of a livable city to meet parking demands and solve traffic congestion, local authorities should develop solutions. In this study, the importance and the benefits of choosing the optimum route for onstreet parking points using geospatial technologies were examined. Optimum routes were chosen for different scenarios with network analysis, on Fabrikalar Street in Eskibağlar Neighborhood, and Kızılcıklı Mahmut Pehlivan Street in Hoşnudiye Neighborhood, which was selected as the study area in Tepebaşı District in Eskişehir Province. As a result of this study, instant dynamic search simulation was applied in Geographic Information Systems (GIS) network analysis and was observed that the method reduced parking search time to a minimum.
\end{abstract}

(c) Afyon Kocatepe Üniversitesi

\section{Giriş}

Coğrafi Bilgi Sistemleri (CBS) konumsal ve konumsal olmayan coğrafi verilerin çalışma amaçlarına uygun bir şekilde toplanması, depolanması, analizi ve kullanıcılara sunulması işlemlerini bir arada gerçekleştiren bir karar destek sistemidir.
Navigasyon uygulamalarında kullanılan güzergâhın çeşitli analizlerle belirlenmesinde ve sonuçların kullanıcılara sunulmasında CBS etkin bir şekilde kullanılmaktadır (Durduran vd., 2018). CBS'nin network analizi aracı kullanılarak herhangi bir yol ağı ile en kısa yol analizi, itfaiye merkezlerine, polis 
karakollarına, hastanelere erişebilirlik, ürün dağıtım güzergahlarının belirlenmesi, servis ağlarının analizi gibi sorunlara çözümler sunulmaktadır (Varol, vd., 2010).

Yerleşim yerlerinde meydana gelen düzensiz büyüme ve bunun etkisiyle ortaya çıkan altyapı yetersizliği, yapıların yerleşim yerlerinin belirli bölgelerinde yoğunlaşması gündelik hayatta önemli ulaşım sorunlarının ortaya çıkmasına neden olmaktadır. Genellikle ihtiyaçlarımızı giderebilmek için alışveriş merkezlerini, alışveriş yapabileceğimiz mağaza ve dükkânların yoğun olarak bulunduğu bölgelere ulaşımda şahsi araçların kullanımı nedeniyle otopark sorunu ortaya çıkmaktadır. Araçların gelişi güzel yol kenarlarına park edilmesi yolların daralmasına, dolayısı ile trafikte yoğunluk ve sıkışıklıklara neden olmaktadır (Özdemir, 2006; Çiçek, 2015).

Yerleşim yerlerinde yeteri kadar otopark alanının bulunmaması ve denetimlerin yetersiz olması otopark sorununu çözülmez bir sorun haline getirmektedir (Güngör, 2006; Çiçek, 2015). Yerleşim yerlerinde yaşanan trafik yoğunluğunun nedenlerinden biri de mevcut otopark alanlarının sürücüler tarafından etkin şekilde kullanılmamasıdır (Güngör, 2006; Çiçek, 2015). Diğer bir sorun yol kenarlarında bulunan iş yerlerinin iş yeri önlerini çeşitli şekillerde işgal etmeleri sonucunda yol kenarı park alanlarının kullanımını engellemekte ve yeni park yeri arayan sürücülerin trafikte yoğunluğa sebep olmasını tetiklemektedir (Güngör, 2006; Çiçek, 2015). İ̧̧ yeri sahiplerinin yol kenarı park alanları konusunda duyarlı davranmaları için bilinçlendirilmeleri ve denetimlerin artması bu sorunun azaltılmasına katkı sağlayacaktır (Güngör, 2006; Çiçek, 2015).

Şehirlerde artan araç sayısı ile sosyal faaliyetlerin fazla olduğu bölgelerde, özellikle şehir içinde bulunan alışveriş yerleri ve mağaza yakınlarında park yeri aramaktan dolayı trafikte sıkışıklıklar meydana gelmektedir. Meydana gelen trafik sıkışıklığı zaman kaybı ve fazladan yakıt tüketimi ekonomik kayıplara neden olmaktadır. Kapalı otoparklar, açık otoparklar ve cadde üstü otopark alanlarında boş yer aramak için sürücüler araçları ile geçirdiği süre zarfında trafikteki sıkışıklığı arttırmaktadır. Akıllı otopark sistemleri, boş park alanlarına yönlendirme uygulamaları trafikte yaşanan sıkışıklığı en aza indirgeyecek uygulamalardan biridir. (Bayram, 2007; Çiçek, 2015).

Günlük hayatta geçici araç park alanlarına ihtiyaç, uzun süreli araç park alanlarına ihtiyaçtan daha fazladır. İnsanlar gündelik ihtiyaçlarını giderebilmek için şahsi araçları ile trafiğe katılmaktadır. Bu ihtiyaçların giderileceği alanlardaki işletme sahibi insanların sayısının, ihtiyaçlarını gideren insan sayısından fazla olması kısa süreli park alanlarının ihtiyacının fazla olmasına neden olmaktadır. Ticari faaliyetlerin yapıldığı alanlardaki işletme sahiplerinin araçlarını bu alanlardan uzak park yerlerine park etmesi kısa süreli park ihtiyacının giderilmesinde ve trafikte yaşanan sıkışıklığın azalmasında etkin bir rol oynamaktadır (Selim, 2011; Çiçek, 2015).

Sürücülerin park yeri ararken mevcut trafik yoğunluğuna ek bir yoğunluk oluşturmadan park yeri bulunması sorunu büyük ölçüde azaltacaktır. Illave trafik yoğunluğuna neden olunmaması için otopark alanlarının düzenlenmesi, ulaşılabilirliğinin uygun olması, park alanlarının denetlenmesi ve bu sürecin devamlılığının sağlanması oldukça önemlidir (Yardım ve Ağrikli, 2005; Çiçek, 2015). Ek trafik yoğunluğunun azaltılmasında otoparkların doluluk ve boşluk oranlarının sürücüler tarafından gözlemlenebilir olması sürücüleri oldukça rahatlatacaktır. Örneğin gidilecek herhangi bir yerde bulunan otoparka yapılan yol tarifi sırasında otoparkın doluluk oranının anlık izlenebiliyor olması trafikte yaşanan yoğunluğu azaltabilecek uygulamalardan biridir.

\section{Nesnelerin İnterneti (IoT)}

Gelişen teknoloji sayesinde insanoğlu günlük hayatta zamanla yarışmaktadır. Internetin gelişmesiyle birlikte yapmayı hedeflediğimiz gündelik planların çoğunu kablosuz teknolojiler kullanarak yapabilir hale gelmiş durumdayız. Akıllı 
ev sistemleri, yangın sensörleri, hırsızlık alarm sistemleri, araç takip sistemleri, otopark doluluk oranlarında kullanılan sistemler vb. teknolojiler internetin nesneler ile etkileşimi sayesinde hayatımıza büyük kolaylıklar getirmektedir. Kullanılan birçok sensör sayesinde toplanan veriler amaca uygun sistemler ile kullanıcılara sunulmaktadır. Kullanıcılar verilerin çoğuna anlık olarak ulaşabilmekte ve anında bilgi sahibi olmaktadır.

Nesnelerin internetinin kullanım alanlarından biri de otopark doluluk oranlarının anlık olarak paylaşılması ve sürücülerin yönlendirilmesidir. Otopark doluluk oranlarının takibi için kullanılan sensörler otopark alanlarının daha verimli kullanımı, yönetimi, denetimi ve sürücülerin boş park alanlarına yönlendirmesi şeklinde kullanılarak araç park sorunlarının çözümüne önemli katkılar sağlamaktadır (Ji, vd., 2014; Badii 2019). Yol kenarı, kapalı veya açık otopark alanlarında park yerlerinin doluluk oranlarının gerçek zamanlı olarak internete aktarılmasını ve kullanıcıların park yerlerinin doluluk oranları hakkında bilgilendirilmesi Şekil 1'de gösterilen sensör teknolojileri ile yapılmaktadır (Çiçek, 2015).
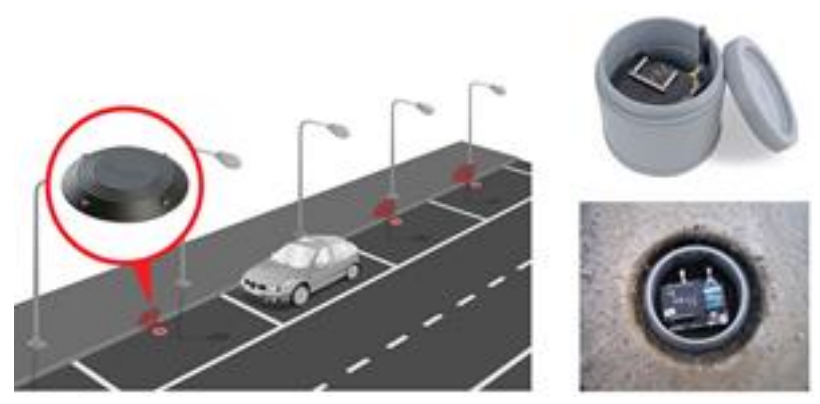

Şekil 1. Yol kenarı otopark alanlarında kullanılan sensörler (int Kyn. 1).

Çeşitli yazılımlarla entegre edilen doluluk sensörleri veri aktarımı sayesinde park yeri ararken trafik yoğunluğunun azaltılmasında etkin rol oynamaktadır. Otopark doluluk sensörleri park verilerini bir merkezde toplayarak sürücülerin kullanmış oldukları yazılımlar yardımıyla park yerlerinin durumları hakkında rehberlik hizmeti yapar. Park yerlerindeki doluluk boşluk verileri bir sistemde toplanır ve otopark yeri arayan sürücülerin kullanmış oldukları yazılımlar ile anlık olarak iletilir.
Böylece boş park yeri ararken meydana gelen trafik yoğunluğu azaltılmaktadır (Khanna ve Anand, 2016).

Nesnelerin interneti (Internet of Things - IoT) teknolojisini kullanan akıllı otopark yönetim sistemleri, cadde-üstü park yerlerinde bulunan sensörler yardımıyla park yerlerinin doluluk boşluk verisini internet sunucusuna aktarmaktadır (Şekil 2). Aktarılan veriler geliştirilen yazııım sayesinde kullanıcı ve yönetici panellerinde gerçek zamanlı olarak takip edilebilmektedir. Navigasyon yazılımı ile entegrasyon sağlanarak sisteme bağlı park yerlerinin lokasyon verilerini, uygun park yeri bilgilerini, tarife, rezarvasyon bilgilerini izleyebilmesi ve seçilen boş park yerine en uygun güzergahın oluşturulması ile kullanıcının park yerine ulaşımı sağlanabilmektedir (Varan ve Karakuş, 2018; Aydın vd.,2017).

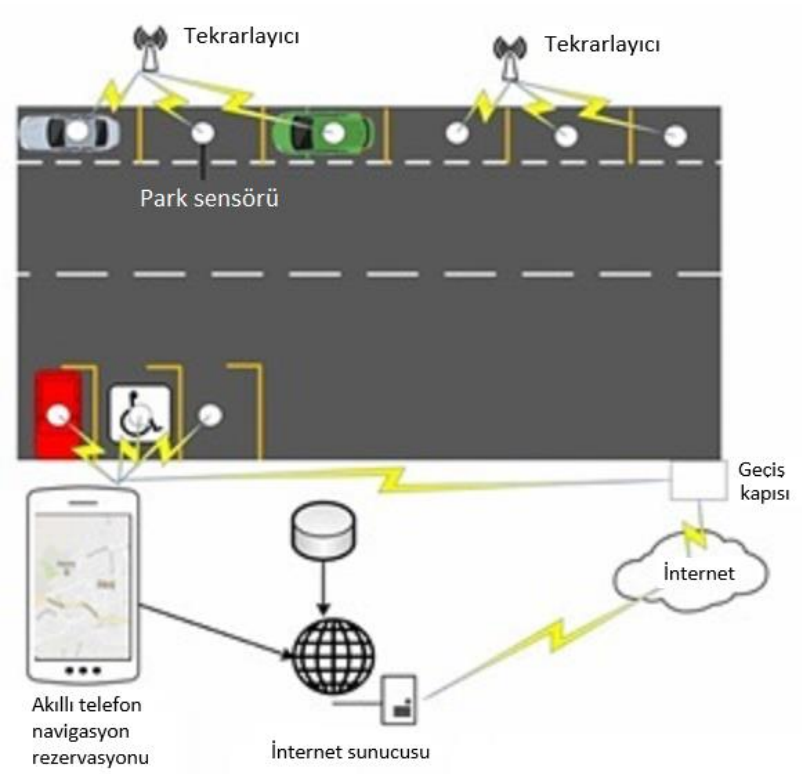

Şekil 2. IoT tabanlı akıllı otopark yönetim sisteminin genel akış şeması (Aydın vd., 2017).

Kullanııının mobil uygulama üzerinden kendine sunulan bilgileri inceleyip; kişisel tercihine uygun park yerini seçerek en kolay ve en kısa sürede park yerine ulaşması mümkün hale gelebilmektedir (Şekil 3). Böylece özellikle kalabalık kentlerde cadde üstü otoparklarda yer bulmak için trafik yoğunluğunun en aza indirilmesi, zaman kaybının önlenmesi ve yakıt tüketiminin azaltılması sağlanacaktır. Bu bağlamda cadde-üstü otopark noktalarının yönetiminde akıllı teknolojilerle güçlendirilmiş IoT tabanlı trafik altyapısı ile entegre akıllı otopark sistemlerine 
geçilmesi kaçınılmaz hale gelmiştir (Hilmani vd., 2018).
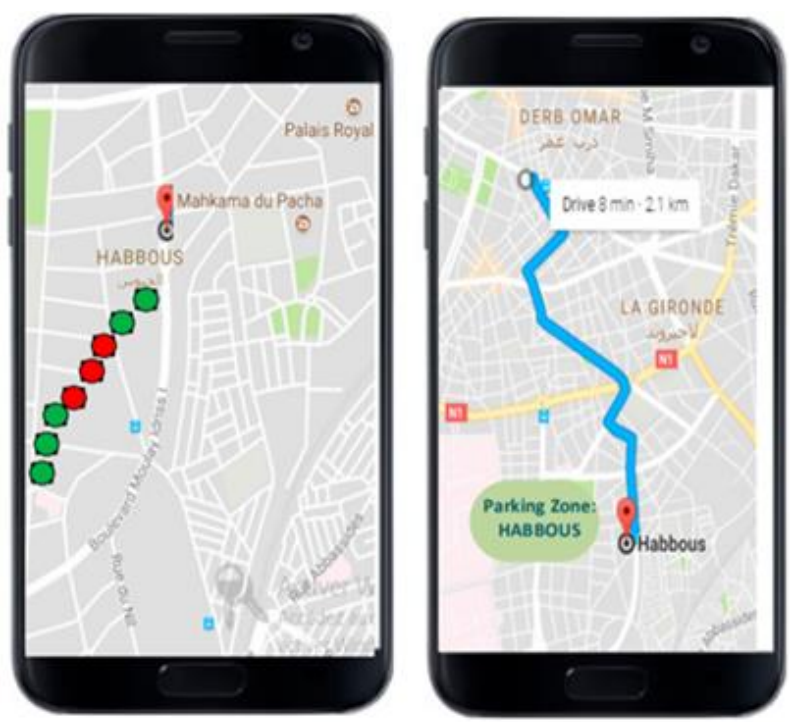

Şekil 3. IoT tabanlı akıllı otopark yönetim sistemlerinde navigasyon uygulaması (Hilmani vd., 2018).

Otopark navigasyon hizmetlerinde en uygun güzergâhın belirlenmesine dönük analizlerin yapılması ve sonuçların mekânsal tabanlı olarak kullanıcılara sunulmasında CBS etkin şekilde kullanılmaktadır. CBS, yaya/araç navigasyon uygulamalarında araç, yol ve trafik durumunu içeren verilerin saklanıp modellenmesi ve çeşitli yöntem ve yazılımlar kullanılarak analizlerin yapılmasına olanak sağlayan entegre sistem çözümleri sunmaktadır (Durduran vd., 2018).

\section{Materyal ve Metot}

Çalışmada cadde-üstü otopark noktalarına yönelik rota optimizasyonu için Eskişehir ilii, Tepebaşı ilıçesi, Eskibağlar Mahallesi, Fabrikalar Caddesi ile Hoşnudiye Mahallesi, Kızılcıklı Mahmut Pehlivan Caddesi çalışma alanı olarak seçilmiştir (Şekil 4). Coğrafi Bilgi Sistemi tabanlı analizlerde ESRI firması tarafından geliştirilen ArcGIS yazılımı ve Network Analyst eklentisi kullanılmıştır. Çalışma alanına ait yolları temsil eden yol orta çizgileri oluşturulmuş ve yol orta çizgilerine paralel $5 \mathrm{~m}$ aralıklarla oluşturulan araç park yeri noktalarının sayısal ortama aktarılması sağlanmıştır. CBS platformuna aktarılan yol ağı üzerinde her bir yol segmentinin uzunluğuna (km) ve hız limitlerine bağlı olarak ulaşım süreleri dakika olarak hesaplanmıştır. Hız limitleri Eskişehir -
Ankara karayolu için $82 \mathrm{~km} / \mathrm{saat}$, bulvarlar ve caddeler için $50 \mathrm{~km} /$ saat olarak alınmıştır.

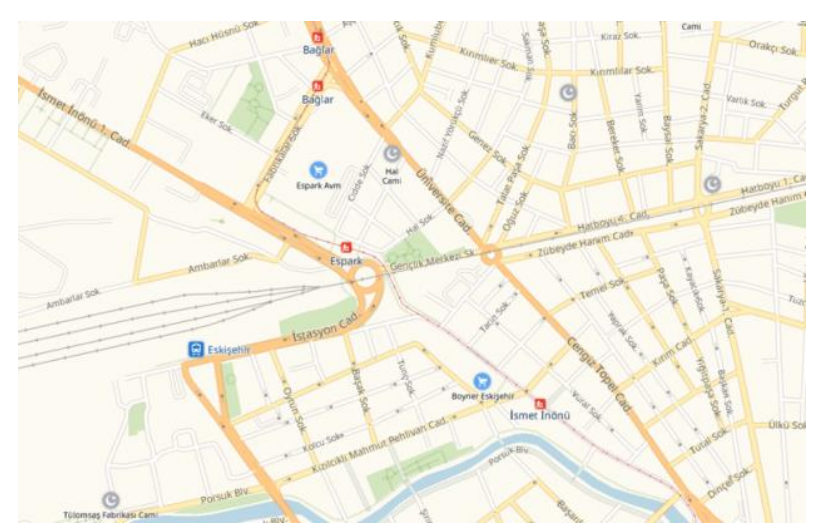

Şekil 4. Çalışma alanı.

Analiz başlangıcında rota optimizasyonu için rastgele Fabrikalar Caddesi üzerindeki araç park yerlerinin 21 tanesi boş, 53 tanesi dolu; Kızılcıklı Mahmut Pehlivan Caddesi üzerinde bulunan otopark noktalarının 26 tanesi boş, 91 tanesi ise dolu olarak kabul edilmiştir. Daha sonra konumsal veritabanında veri seti oluşturularak çeşitli senaryolarla en kısa yol analizleri uygulanmıştır. Hazırlanan veriler ile CBS'nin önemli analizlerinden biri olan ağ analizi yöntemi kullanılarak farklı senaryolarla en kısa yol analizleri yapılmıştır. Senaryolarda kullanılan araç park yerleri dolu kabul edilenler bariyer olarak tanımlanmış, her bir boş araç park yeri için zaman hesaplamaları yapılmıştır.

\section{Bulgular}

\subsection{Senaryo-I}

Başlangıç noktasından Espark AVM'ye hareket etmek isteyen araç kullanıcısı Fabrikalar Caddesi üzerinde yer alan boş park yeri noktalarından 2 numaralı noktayı seçerek, en kısa yoldan boş park yerine ulaşmıştır (Şekil 5,6). Çizelge 1'de boş park yerine olan uzaklık ve varış süresi gösterilmiştir.

Çizelge 1. Fabrikalar Caddesi boş park yerine olan uzaklık ve varış süresi.

\begin{tabular}{ccc}
\hline Otopark Yeri & $\begin{array}{c}\text { Mesafe } \\
(\mathbf{k m})\end{array}$ & $\begin{array}{c}\text { Yaklaşık varış süresi } \\
\text { (dk) }\end{array}$ \\
\hline $\begin{array}{c}\text { Fabrikalar Caddesi } \\
\text { 2 numaralı park } \\
\text { yeri }\end{array}$ & 0.92 & 1.10 \\
\hline
\end{tabular}




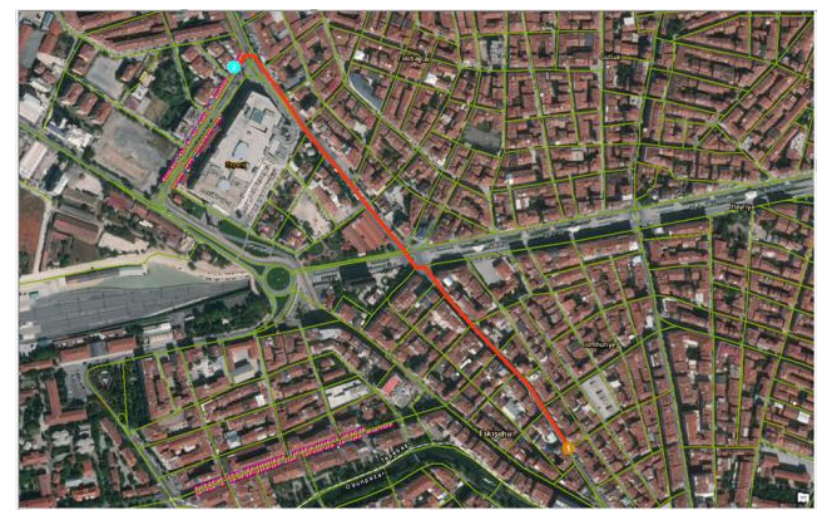

Şekil 5. Fabrikalar Caddesinde yer alan boş park yeri noktasına en kısa yolun bulunması örneği.

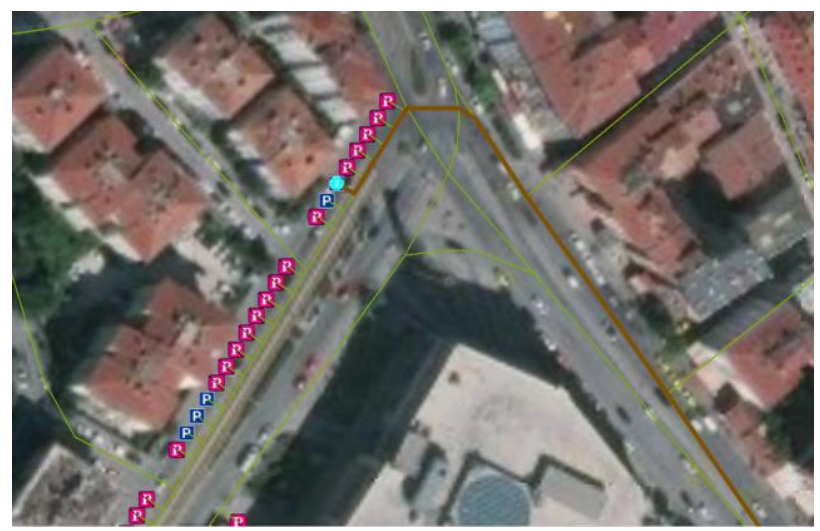

Şekil 6. Fabrikalar Caddesinde yer alan boş park yeri noktasına ulaşımın sağlanması.

\subsection{Senaryo-II}

Bu senaryoda araç kullanıcısı Kızılcıklı Mahmut Pehlivan Caddesine gitmek üzere saat 10:00' da başlangıç noktasından hareket etmiştir. Kullanıcı en kısa yol tarifi almak için cadde üzerinde yer alan 2 numaralı boş park noktasını seçmiştir. Ancak kullanııının seçmiş olduğu boş otopark noktası 10:00:08' de, hemen sonraki 3 numaralı boş otopark noktası da 10:01:20' de başka kullanıcılar tarafından doldurulmuştur. Sistem anlık dinamik arama yöntemi ile kullanıcıya en yakın boş park yeri noktalarından 4 numaralı park noktasını seçerek, en kısa yoldan boş park yerine ulaşmıştır (Şekil 7, 8). Çizelge 2'de boş park yerine olan uzaklık ve varış süresi gösterilmiştir.

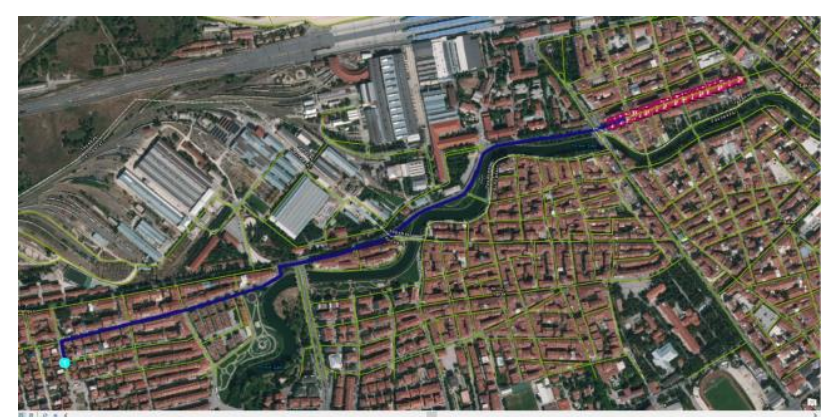

Şekil 7. Kızılcıklı Mahmut Pehlivan Caddesindeki boş araç park yeri için en kısa yolun bulunması örneği.

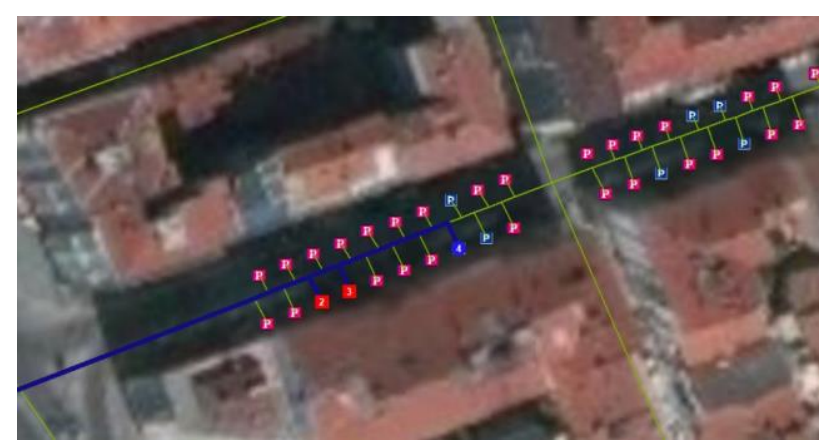

Şekil 8. Kızılcıklı Mahmut Pehlivan Caddesinde yer alan boş park noktasına ulaşımın sağlanması.

Çizelge 2. Kızılcıklı Mahmut Pehlivan Caddesi boş park yerine olan uzaklık ve varış süresi.

\begin{tabular}{ccc}
\hline Otopark Yeri & $\begin{array}{c}\text { Mesafe } \\
(\mathbf{k m})\end{array}$ & $\begin{array}{c}\text { Yaklaşık varış süresi } \\
(\mathbf{d k})\end{array}$ \\
\hline $\begin{array}{c}\text { Fabrikalar Caddesi } \\
\text { 2 numaralı park } \\
\text { yeri }\end{array}$ & 1.71 & 2.05 \\
\hline
\end{tabular}

\subsection{Senaryo-III}

Bu senaryoda araç kullanıcısı Kızılcıklı Mahmut Pehlivan Caddesine gitmek üzere saat $12: 40^{\prime}$ da başlangıç noktasından hareket etmiştir. Kullanıcı en kısa yol tarifi almak için cadde üzerinde yer alan 3 adet boş park noktasından 2 nolu park noktasını seçmiştir. Ancak kullanıcının seçmiş olduğu boş otopark noktası 12:40:49' da, diğer boş otopark noktaları 3 ve 4 nolu noktalar sırasıyla 12:40:15 ve 12:40:35'de başka kullanıcılar tarafından doldurulmuştur. Sistem Kızılcıklı Mahmut Pehlivan Caddesi üzerinde boş park yeri olmadığından anlık dinamik arama yöntemi ile sürücüyü Fabrikalar Caddesi üzerindeki en yakın boş park yeri noktalarından 5 numaralı noktayı seçerek, en kısa yol tarifini oluşturmuştur. Kullanıcı sistemin belirlemiş olduğu yol tarifi üzerinden Fabrikalar Caddesindeki 5 numaralı park noktasına ilerlerken; 5 numaralı nokta 12:40:58' de ve hemen yakınındaki 
6 numaralı boş nokta da 12:41:22' de başka kullanıcılar tarafından doldurulmuştur. Sistem kullanıcıya boş park yeri noktalarından en yakın olanı 7 numaralı noktayı seçerek, en kısa yoldan boş park yerine ulaşmıştır (Şekil 9-11). Çizelge 3'te boş park yerine olan uzaklık ve varış süresi gösterilmiştir.

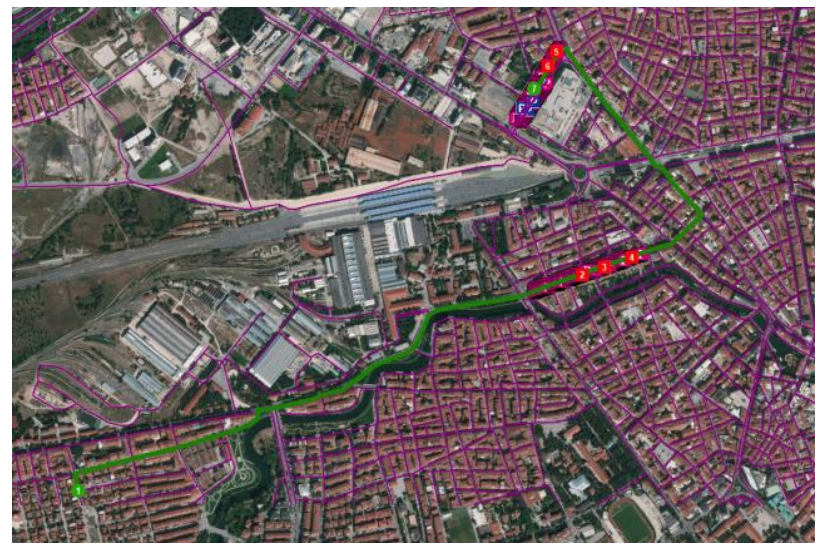

Şekil 9. Üçüncü senaryoya göre boş park noktasına en kısa yolun bulunması örneği.

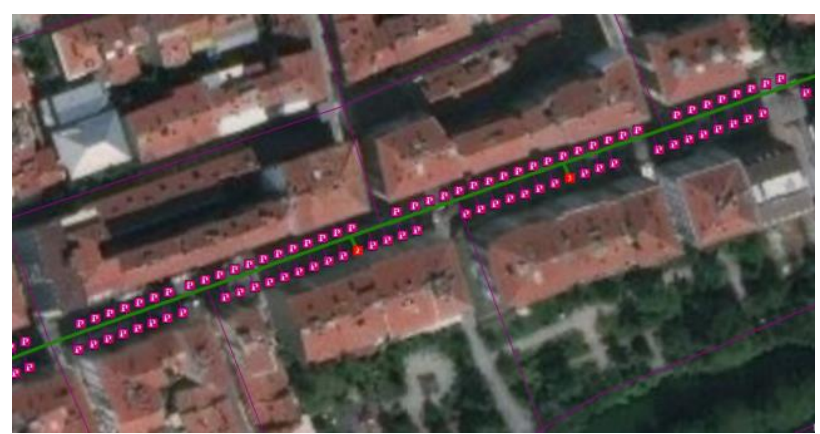

Şekil 10. Üçüncü senaryoya göre Kızılcıklı Caddesinde boş park yerlerinin dolması sonucu kullanıcının Fabrikalar Caddesine yönlendirilmesi.

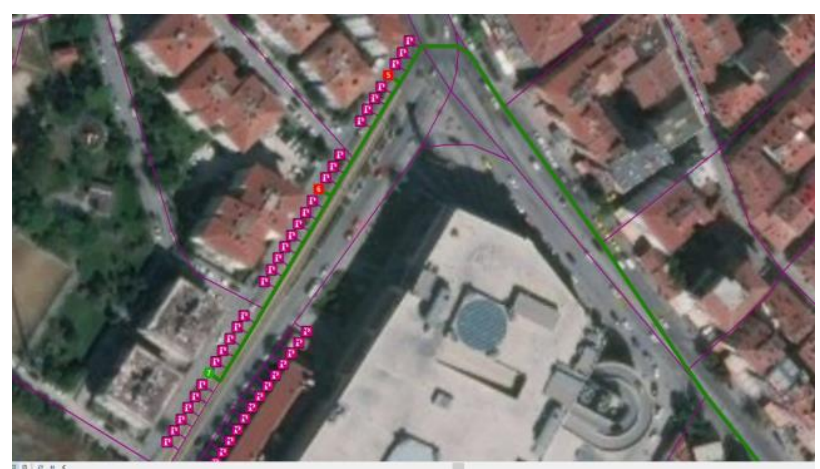

Şekil 11. Üçüncü senaryoya göre Fabrikalar Caddesinde boş park yeri noktasına ulaşımın sağlanması
Çizelge 3. Kızılcıklı Mahmut Pehlivan Caddesi boş park yerine olan uzaklık ve varış süresi.

\begin{tabular}{ccc}
\hline Otopark Yeri & $\begin{array}{c}\text { Mesafe } \\
\text { (km) }\end{array}$ & $\begin{array}{c}\text { Yaklaşık varış süresi } \\
\text { (dk) }\end{array}$ \\
\hline $\begin{array}{c}\text { Fabrikalar Caddesi } 7 \\
\text { numaralı park yeri }\end{array}$ & 3.11 & 3.73 \\
\hline
\end{tabular}

\section{Tartışma ve Sonuç}

Şehirlerde artan nüfus ve araç sayısı ulaşımı olumsuz yönde etkilemektedir. Ulaşım sorunlarının artmasının en önemli nedenlerinden biri, artan araç sayısına oranla otopark yerlerinin yetersiz olmasıdır. Araç park yeri bulamayan sürücüler park yeri ararken trafikte yoğunluğa neden olmaktadır. Çalışmada sorunun çözümünün araç park alanlarının doluluk/boşluk oranına göre sürücülerin yönlendirilmesiyle azaltılabilir olduğu ortaya konmuştur. Bu bağlamda CBS uygulamalarında kullanılan ağ analizi aracı ile sürücüler boş otopark alanlarına en kısa yoldan yönlendirilerek trafikte yaşanan yoğunluğun azaltılabileceği, sürücülerin boş park yerleri arama sırasında meydana getirdikleri yoğunluğun en aza indirgeneceği sonucuna varılmıştır.

Eskişehir yerleşim yeri içerisinde seçilen çalışma alanı için üç farklı senaryo ile ağ analizi yöntemi kullanılmıştır. Üç farklı senaryo ile araç park yerlerinin doluluk ve boşluk oranına göre sürücüleri yönlendirerek uygun park alanlarına en kısa yoldan gidilmesi hedeflenmiştir. Analizler sonucunda araç sürücüleri üç farklı konumdan harekete başlamış ve en uygun yolu kullanarak boş otopark alanlarına yönlendirilmiştir. Çalışmada anlık dinamik sorgulama simülasyonu yapılmış ve sürücülerin park yeri ararken harcadıkları zamanı en aza indirgenerek uygun park yerlerine ulaşmaları sağlanmıştır. Benzer uygulamaların trafikte yaşanan yoğunluğun ve acil durumlarda yaşanabilecek sorunları azaltacağı, boş park yeri ararken harcanan zamanın azaltılması beraberinde yakıt tasarrufu sağlayacağı düşünülmektedir.

Gelecek çalışmalarda anlık trafik yoğunluğunu göz önünde bulundurarak en kısa yol analizlerinde zaman hesaplamaları yapılması hedeflenmektedir. Nesnelerin interneti (IoT), makine öğrenmesi, yapay zekâ (Al) vb. teknolojilerin coğrafi bilgi teknolojileri 
ile entegrasyonu güncel hayatta çözümler üretebilmektedir. Bu teknolojilerin kullanımının yaygınlaştırılması, sağlayacağı yararlar göz önünde bulundurulduğunda kaçınılmaz olduğu görülmektedir.

\section{Kaynaklar}

Aydın, i., Karaköse, M. and Karaköse, E., 2017. A navigation and reservation based smart parking platform using genetic optimization for smart cities. 5th International İstanbul Smart Grid and Cities Congress and Fair (ICSG), 19-21 Nisan 2017, İstanbul.

Badii, C., Bellini, P., Difino, A. and Nesi, P., 2019. Siimobility: An iot/ioe architecture to enhance smart city mobility and transportation services. Sensors, 19 (1), 1.

Bayram, M., 2007. Elektronik kartlı temelli olarak otopark otomasyon sisteminin gerçekleştirilmesi. Yüksek Lisans Tezi, Gazi Üniversitesi Bilişim Enstitüsü, Ankara, 55.

Çiçek, C. 2015. Otoparklarda kullanılan yeni teknolojilerin Türkiye'de uygulanabilirliğinin araştırılması. Yüksek Lisans Tezi, Eskişehir Osmangazi Üniversitesi Fen Bilimleri Enstitüsü, Eskişehir, 122.

Durduran, S..S. Gümüş, G.G., Bozdağ, A., ve Beyhan, C.H., 2018. Coğrafi bilgi sistemleri kullanarak yaya yolları üzerinden rota optimizasyonu. Ömer Halisdemir Üniversitesi Mühendislik Bilimleri Dergisi, 7,(1), 180189

Güngör, E. K., 2006. Konya şehir merkezinde otopark sorunu ve öneriler. Yüksek Lisans Tezi, Selçuk Üniversitesi Fen Bilimleri Enstitüsü, Konya, 137.

Hilmani, A., Maizate, A. and Hassouni, L., 2018. Designing and managing a smart parking systemusing wireless sensor networks. Journal of Sensor and Actuator Networks, 7,24.

Ji, Z., Ganchev, I., O'Droma, M., Zhao, L. and Zhang, X., 2014. A cloud-based car parking middleware for lotbased smart cities: Design and implementation. Sensors, 14, 22372-22393.

Khanna, A. and Anand, R. 2016. lot based smart parking system. International Conference on Internet of Things and Applications (IOTA), pp. 266-270, 22-24 January 2016, India.

Özdemir, V. İ., 2006. Park et ve devam et tesisleri ve harem otoparkı örneği. Yüksek Lisans Tezi, Yıldız Teknik Üniversitesi Fen Bilimleri Enstitüsü, İstanbul, 96.
Selim, C., 2011. Otopark alanlarının planlama ve tasarım ilkeleri: Ege üniversitesi yerleşke örneği. Yüksek Lisans Tezi, Ege Üniversitesi Fen Bilimleri Enstitüsü, İzmir, 183.

Varan, M. ve Karakuş C., 2018. Sakarya şehri için dış ve iç yönlendirmeli rezervasyon tabanlı otopark yönetim sistemi tasarımı ve sistem başarımı. Sakarya Üniversitesi Fen Bilimleri Enstitüsü Dergisi, 22 (1), 6674.

Varol, T., Özel, H. B. ve Macaroğlu, K., 2010. Network analizinin orman yangınlarında kullanım olanakları (Yenihan orman işletme şefliği örnek çalışması). III. Ulusal Karadeniz Ormancılık Kongresi, 20-22 Mayıs 2010, Artvin.

Yardım, M. S. ve Ağrikli, M., 2005. Otomatik otoparklar ve Türkiye'deki otopark probleminin çözümü için uygulama potansiyeli. 6. Ulaştırma Kongresi, TMMOB İnşaat Mühendisleri Odası İstanbul Şubesi, İstanbul.

\section{internet kaynakları}

1-http://www.libelium.com/smart_parking, (06.11.2018) 